\title{
Pemanfaatan Agregat Sungai Mawa Kecamatan Cendana Dalam Campuran AC-WC
}

\author{
Irene Sion Kondo Sosang ${ }^{\star 1}$, Alpius ${ }^{\star 2}$, Elizabeth ${ }^{\star 3}$ \\ *1 Mahasiswa Program Studi Teknik Sipil, Universitas Kristen Indonesia Paulus, Makassar, Indonesia \\ reneirene465@gmail.com \\ *2,3 Dosen Program Studi Teknik Sipil, Universitas Kristen Indonesia Paulus, Makassar, Indonesia \\ alpiusnini@gmail.com dan elizabethbongga@yahoo.com
}

\begin{abstract}
ABSTRAK
Penelitian ini di maksudkan untuk menguji karakteristik campuran $A C$-WC dengan memanfaatkan agregat dari sungai Mawa Kecamatan Cendana. Metode dalam penelitian ini adalah melakukan serangkaian pengujian karakteristik berupa agregat halus, kasar, dan filler lalu merancang komposisi campuran kemudian pembuatan benda uji berupa campuran $A C$-WC serta pengujian Marshall untuk mendapatkan karakteristik campuran dan pengujian Marshall Immersion untuk mendapatkan Indeks Perendaman (IP) / Indeks Kekuatan Sisa (IKS) / Durabilitas campuran yang berkadar aspal optimum. Hasil penelitian menunjukkan bahwa karakteristik bahan perkerasan berupa agregat dari sungai Mawa Kecamatan Cendana memenuhi spesifikasi sebagai bahan lapisan permukaan jalan. Melalui uji Marshall diperoleh karakteristik campuran AC-WC dengan kadar aspal 5\%,5,5\%, 6\%, 6,5\%, 7\% memenuhi persyaratan yang dikeluarkan oleh Direktorat Jenderal Bina Marga Departemen Pekerjaan Umum Republik Indonesia, Spesifikasi Umum 2018. Hasil pengujian Marshall Immersion campuran AC-WC pada kadar aspal optimum 7\% mendapatkan Indeks Perendaman (IP) / Indeks Kekuatan Sisa (IKS) / Durabilitas campuran sebesar 94,81\% yang berarti melampaui syarat batas yaitu $\geq 90 \%$ sehingga campuran tahan terhadap perendaman dalam air.
\end{abstract}

Kata Kunci : karakteristik, Ac-Wc, Marshall

\section{ABSTRACT}

This research is intended to examine the characteristics of AC-WC mixture by utilizing aggregates from the Mawa river, Cendana District. The method in this research is to conduct a series of characteristics testing in the form of fine aggregates, coarse, and fillers then design the composition of the mixture then manufacture test specimens in the form of AC-WC mixture and Marshall test to obtain the mixture characteristics and Marshall Immersion test to obtain an Immersion Index (IP) / Index Residual Strength (IKS) / Durability of mixes with optimum asphalt content. The results of the study showed that the characteristics of the pavement material in the form of aggregates from the Mawa river, Cendana District meet the specifications as road surface lining materials. Through the Marshall test the AC-WC mixture characteristics obtained with asphalt content of 5\%, 5.5\%, 6\%,6.5\%,7\% meet the requirements issued by the Directorate General of Highways of the Ministry of Public Works of the Republic of Indonesia, General Specifications 2018. Results Marshall Immersion testing of AC-WC mixture at optimum asphalt content of 7\% gets an Immersion Index (IP) / Residual Strength Index (IKS) / Durability of a mixture of $94.81 \%$ which means it exceeds the boundary requirement of $\geq 90 \%$ so the mixture is resistant to immersion in water .

Keywords: Characteristics, Ac-Wc, Marshall

\section{PENDAHULUAN}

Batu sungai adalah bongkahan batu yang umumnya ukurannya tidak beraturan yang didapatkan dari Sungai. Batu Sungai juga kini banyak dimanfaatkan sebagai agregat untuk campuran konstruksi, salah satunya konstruksi perkerasan jalan [1]. Pesatnya pembangunan prasarana jalan mengakibatkan meningkatnya kebutuhan bahan- bahan yang digunakan, termasuk pemakaian agregat, Sehingga banyak agregat, didatangkan dari daerah lain akibatnya biaya yang dikeluarkan cukup banyak. Sedangkan sumber daya alam yang ada di sekitar
Sungai Mawa Kecamatan Cendana, Kota Palopo memiliki banyak material berupa batu sungai. Agregat batu sungai dapat digunakan sebagai bahan pembangunan perkerasan jalan, untuk mengurangi biaya pengeluaran. Dengan memanfaatkan sumber daya alam yang ada di sekitar juga memberikan penghasilan tambahan bagi masyarakat sekitar. Pembangunan prasarana transportasi jalan setiap tahun mengalami peningkatan, demi menunjang pembangunan yang merata sampai ke daerah terpencil. Pemerintah Daerah mendorong penggunaan bahan lokal setempat perlu diprioritaskan. Untuk memenuhi kebutuhan tersebut 
maka perlu memanfaatkan sumber daya alam yang ada di sekitar pembangunan jalan, seperti pada daerah Sungai Mawa Kecamatan Cendana merupakan daerah yang memiliki sumber material berupa batu Sungai yang selama ini banyak digunakan konstruksi bangunan dan perkerasan jalan namun masih belum diteliti secara spesifik mengenai campuran AC-Wc.Tujuan penelitian yaitu untuk mengetahui agregat dari Sungai Mawa, Kecamatan Cendana memiliki nilai karakteristik yang memenuhi spesifikasi Umum Bina Marga 2018, mengetahui komposisi campuran AC-WC yang mengunakan agregat dari Sungai Mawa [2], Kecamatan Cendana, dan untuk mengetahui pemanfaatan dalam campuran AC- WC dengan metode pengujian Marshall Konversional dan mengetahui nilai Indeks Kekuatan Sisa (IKS) melalui pengujian Marshall Immersion.

Lapisan Permukaan adalah suatu lapisan yang langsung berhubungan dengan beban (roda kendaraan) [3][4]. Lapis permukaan ini sudah termasuk sebagai lapis aus, tetapi tidak jarang ada beberapa lapisan permukaan ditambah dengan lapis aus. Karena kontak langsung dengan beban kendaraan maka lapisan ini akan mengalami tekanan geser, dan memiliki daya tahan yang cukup baik. Lapis permukaan itu sendiri masih bisa dibagi lagi menjadi tiga lapisan lagi, yaitu: lapis aus (Wearing Course) merupakan bagian dari lapis permukaan yang terletak di atas lapis antara (binder course) yang berhubungan langsung dengan ban kendaraan., lapis antara (Binder Course) merupakan bagian dari permukaan yang terletak di antara lapis pondasi atas (Base Course) dengan lapis aus (Wearing Course), dan lapisan pondasi atas adalah lapisan yang diletakkan antara lapisan pondasi bawah dan lapisan pemukaan [5].

Beberapa penelitian sebelumnya yang meneliti pemanfaatan material local antara lain $\mathrm{R}$ Rachman meneliti Pemanfaatan Batu Gunung Bottomale Toraja Utara sebagai Campuran Laston [6]. Fany meneliti Pemanfaatan Agregat Sungai Wanggar Kabupaten Nabire Sebagai Bahan Campuran AC-WC dan AC-BC [7]. Alpius meneliti Campuran HRS-WC Menggunakan Agregat Batu Gunung Desa Palipu Kecamatan Mengkendek Tana Toraja [8]

\section{METODOLOGI PENELITIAN}

\section{Lokasi dan Waktu Penelitian}

Lokasi tempat pengambilan material diambil dari Sungai Mawa, Kecematan Cendana Kota Palopo Provinsi Sulawesi Selatan. Akses jalan menuju pengambilan material ini sudah bisa dilalui dengan menggunakan kendaraan beroda dua maupun beroda empat, akan tetapi akses jalan menuju lokasi masih terdapat beberapa kerusakan jalan. Lokasi pengambilan material dapat dilihat pada Gambar 1.

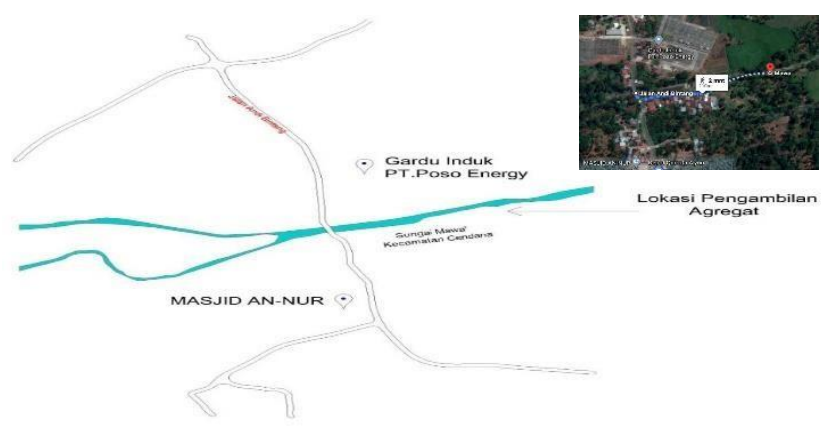

Gambar 1. Lokasi pengambilan material

\section{Pemeriksaan Karakteristik Bahan}

Perancangan dan pengujian karakteristik campuran beraspal harus mengikuti standar/spesifikasi yang ada. Untuk Indonesia, standar/spesifikasi yang digunakan adalah spesifikasi Umum Bina Marga 2018.

Rancangan pengujian didahului pengujian karakteristik bahan. Jika hasil pengujian tidak sesuai spesifikasi (berat jenis, keausan dan kelekatan) maka agregat tidak boleh digunakan juga jika karakteristik campuran tidak memenuhi spesifikasi maka campuran tersebut tidak boleh di produksi ( kecuali dilakukan modifikasi dengan bahan tambah) jika memenuhi spesifikasi maka dilanjutkan dengan rancangan campuran.

\section{a. Karakteristik agregat}

Standar rujukan/acuan pemeriksaan Analisa saringan agregat kasar dan agregat halus mengacu pada metode atau standar SNI ASTM C136:2012. Pemeriksaan berat jenis dan penyerapan agregat kasar mengacu pada standar rujukan SNI 1969:2016 dan Pemeriksaan berat jenis dan penyerapan air agregat halus mengacu pada standar rujukan SNI 1970:2016. Standar rujukan/acuan pemeriksaan kadar lumpur dan SE (Sand Equivalent) mengacu pada standar rujukan SNI 03-4428-1997. Pengujian Keausan (Abration) ini mengacu pada standar rujukan SNI 2417-2008. Pemeriksaan partikel kepipihan dan kelonjongan mengacu pada standar rujukan ASTM D - 4791-10 dengan perbandingan 1:5. Pemeriksaan agregat lolos ayakan No. 200 mengacu pada standar rujukan SNI ASTM C117:2012.

\section{b. Karakteristik Aspal}

Pengujian Penetrasi pada $25^{\circ} \mathrm{C}$ merujuk pada SNI 2456:2011; Pengujian Titik Nyala merujuk SNI 2433:2011; Pengujian Titik Lembek $\left({ }^{\circ} \mathrm{C}\right)$ SNI2434;2011; Pengujian Berat Jenis SNI 2441:2011; Pengujian Daktilitas pada $25^{\circ} \mathrm{C}$ SNI 2432:2011; Pengujian Berat yang Hilang (\%) menggunakan SNI06-2441-1991.

\section{c. Komposisi Campuran}


Campuran beraspal menggunakan 3 (tiga) bahan utama yaitu agregat, aspal, dan filler. Untuk memenuhi karakteristik campuran beraspal, maka rancangan campran harus mengikuti spesifikasi Umum Bina Marga 2018.

Yang utama dalam rancangan campuran adalah Gradasi dari campuran itu sendiri,sehingga untuk mendapatkan karakteristik campuran yang baik maka gradasi yang digunakan yaitu gradasi ideal dengan mengambil nilai tengah dari batasan gradasi (batas atas dan bawah gradasi/ rata-rata batas gradasi) yang dapat dilihat berikut :

Tabel 1. Rancangan komposisi campuran

\begin{tabular}{lccccc}
\hline $\begin{array}{l}\text { Kadar aspal } \\
\text { rancangan }\end{array}$ & $\mathbf{1}$ & $\mathbf{2}$ & $\mathbf{3}$ & $\mathbf{4}$ & $\mathbf{5}$ \\
\cline { 2 - 6 }$(\%)$ & (a) & (b) & (c) & (d) & (e) \\
\cline { 2 - 6 } \multicolumn{1}{c}{} & 5,00 & 5,50 & 6,00 & 6,50 & 7,00 \\
\hline $\begin{array}{l}\text { Berat aspal } \\
\text { (gr) }\end{array}$ & 60,00 & 66,00 & 72,00 & 78,00 & 84,00 \\
\hline
\end{tabular}

\section{Teknik Analisis Data}

Dalam hal ini pengolahan data-data hasil survei dalam bentuk numerik dan akan dianalisis dengan rumus empirik statistika-matematis. Adapun tahapantahapan teknik analisis data dijelaskan sebagai berikut:

\section{a. Analisis Karakteristik Agregat}

Pada tahap ini dilakukan analisis karakteristik agregat dengan standar spesifikasi Bina Marga.

b. Analisis Regresi

Pada tahap ini dilakukan analisis regresi hubungan antara variabel yang menjadi karakteristik campuran.

\section{ANALISIS DAN PEMBAHASAN}

\section{Hubungan Kadar Aspal Terhadap VIM}

Semakin tinggi kadar aspal yang digunakan maka nilai VIM semakin kecil begitu pula sebaliknya, apabila kadar aspal yang digunakan semakin kecil maka nilai VIM akan semakin besar, kerena aspal berfungsi sebagai pengikat dan pengisi rongga di dalam campuran beraspal. VIM mencapai batas minimum yaitu $3 \%$ pada kadar aspal 7,103\% dan VIM mencapai batas maksimum yaitu $5 \%$ pada kadar aspal 4,69 \%. Hubungan kadar aspal dan VIM dapat dilihat pada Tabel 1 dan Gambar 2.

Tabel 1. Hubungan kadar aspal terhadap VIM

\begin{tabular}{cccccccc}
\hline $\begin{array}{c}\text { Kadar } \\
\text { Aspal }\end{array}$ & 4,69 & 5 & 5,5 & 6 & 6,5 & 7 & 7,10 \\
\hline VIM & 5,00 & 4,74 & 4,32 & 3,90 & 3,49 & 3,08 & 3,00 \\
\hline Persyaratan & & & & $3-5 \%$ & & & \\
\hline
\end{tabular}

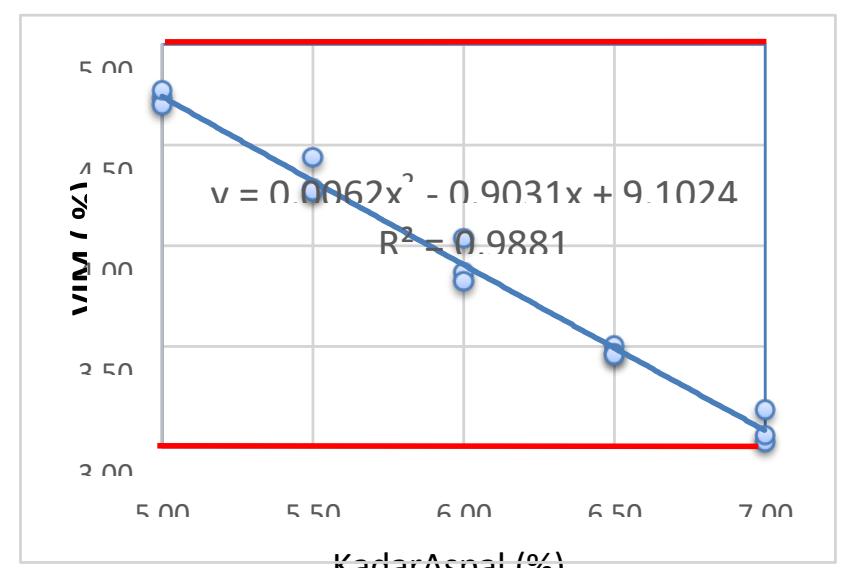

Gambar 2. Hubungan kadar aspal terhadap VIM

\section{Hubungan Kadar Aspal Terhadap Stabilitas}

Penggunaan kadar aspal yang sedikit dalam campuran AC-WC akan menghasilkan selimut aspal yang tipis pada permukaan agregat yang mengakibatkan ikatan antar agregat (Interlocking) menjadi lemah sehingga stabilitas campuran kecil, tetapi jika aspal bertambah lagi maka selimut aspal menjadi tebal sehingga ikatan antar agregat menjadi kuat/stabilitas campuran besar. Berdasarkan pada kadar aspal 5\% dan akan kembali turun pada kadar aspal $6.5 \%$. Pada persamaan garis menunjukan bahwa Stabilitas maksimum berada pada kadar aspal $5,9 \%$ dengan nilai stabilitas sebesar 2088,88 $\mathrm{kg}$. Hubungan kadar aspal dan stabilitas dapat dilihat pada Gambar 3 dan Tabel 2.

Tabel 2. Hubungan kadar aspal terhadap stabilitas

\begin{tabular}{ccccccc}
\hline $\begin{array}{c}\text { Kadar } \\
\text { Aspal }\end{array}$ & $\mathbf{5}$ & $\mathbf{5 , 5}$ & $\mathbf{5 , 9}$ & $\mathbf{6}$ & $\mathbf{6 , 5}$ & $\mathbf{7}$ \\
\hline Stabilitas & 1696,7 & 2015,4 & 2093,8 & 2088,8 & 1917,0 & 1499,8 \\
\hline $\begin{array}{c}\text { Persyarata } \\
\text { n }\end{array}$ & & \multicolumn{5}{c}{ Min 800 kg } \\
\hline
\end{tabular}

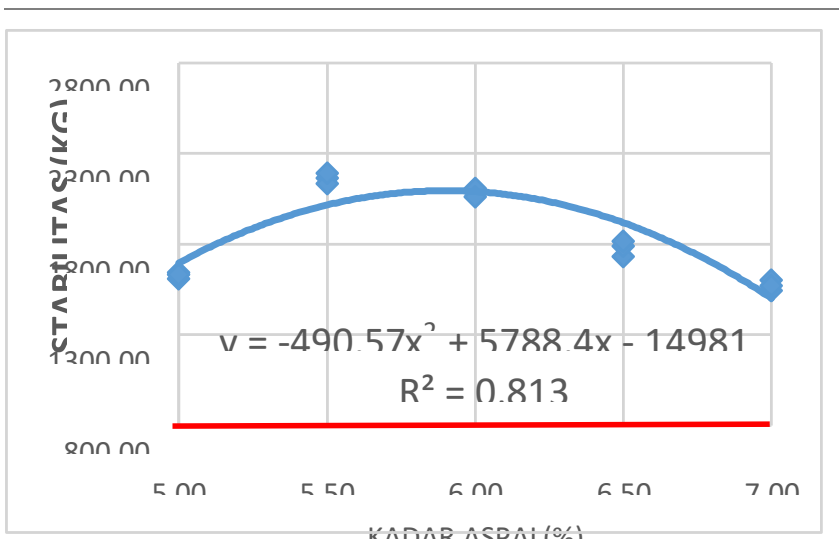

Gambar 3. Hubungan kadar aspal terhadap stabilitas

\section{Hubungan Kadar Aspal Terhadap Flow}

Jika penggunaan aspal dalam campuran beraspal kecil maka ikatan antar agregatnya berkurang yang menyebabkan kelelehan besar. Tetapi jika penggunaan aspal bertambah banyak maka ikatan 
antar agregat dalam campuran menjadi lebih kuat yang mengakibatkan kelelehan campuran menurun, kemudian jika penggunaan aspal bertambah banyak lagi maka selimut aspal menjadi lebih tebal yang mengakibatkan kekuatan campuran berkurang. Hubungan kadar aspal terhadap flow dapat dilihat pada Tabel 3 dan Gambar 4.

Tabel 3. Hubungan kadar aspal terhadap flow

\begin{tabular}{ccccccc}
\hline Kadar Aspal & $\mathbf{5}$ & $\mathbf{5 , 5}$ & $\mathbf{5 , 5 9}$ & $\mathbf{6}$ & $\mathbf{6 , 5}$ & $\mathbf{7}$ \\
\hline Flow & 3,00 & 2,82 & 2,81 & 2,90 & 3,25 & 3,86 \\
\hline Persyaratan & \multicolumn{7}{c}{$2-4 \mathrm{~mm}$} \\
\end{tabular}

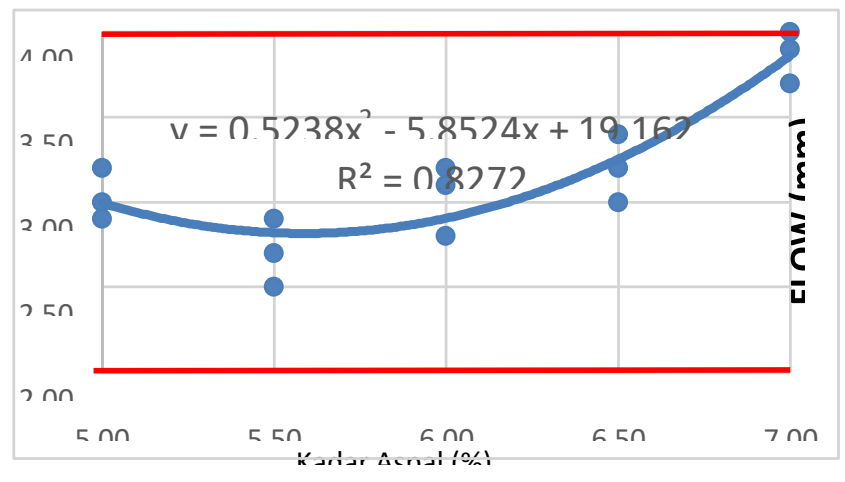

Gambar 4. Hubungan kadar aspal terhadap flow

\section{Hubungan Kadar Aspal Terhadap VMA}

Semakin banyak aspal yang di gunakan maka rongga dalam agregat yang terisi aspal semakin besar sehingga nilai VMA akan meningkat. Berdasarkan persamaan garis kurva bahwa VMA mencapai batas mininum yaitu $14 \%$ pada kadar aspal 4,289\%. Hubungan kadar aspal dan VMA dapat dilihat pada Tabel 4 dan Gambar 5.

Tabel 4. Hubungan kadar aspal terhadap VMA

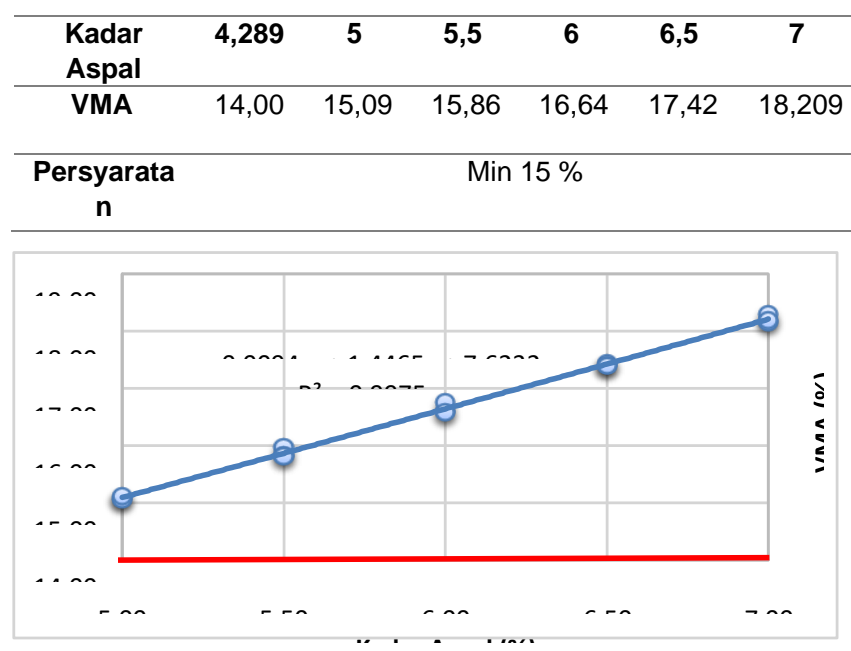

Gambar 5. Hubungan kadar aspal terhadap VMA

\section{Hubungan Kadar Aspal Terhadap VFB}

Untuk tujuan bekerja, antara pukul 07.00-08.00 WITA Penggunaan kadar aspal yang sedikit mengurangi
VFB, penggunaan kadar aspal yang banyak memperbesar VFB. Di mana aspal dalam campuran akan mengisi semua rongga yang ada dalam campuran dan dalam agregat. Pada kadar aspal $3,19 \%$ nilai VFB berada pada batas minimum yaitu 65 $\%$. Hubungan kadar aspal dan VFB dapat dilihat pada Tabel 5 dan Gambar 6.

Tabel 5. Hubungan kadar aspal terhadap VFB

\begin{tabular}{ccccccc}
\hline $\begin{array}{c}\text { Kadar } \\
\text { Aspal }\end{array}$ & $\mathbf{3 , 1 9}$ & $\mathbf{5}$ & $\mathbf{5 , 5}$ & $\mathbf{6}$ & $\mathbf{6 , 5}$ & $\mathbf{7}$ \\
\hline VFB & 65,00 & 103,7 & 115,2 & 127,1 & 139,3 & 151,9 \\
\hline $\begin{array}{c}\text { Persyarat } \\
\text { an }\end{array}$ & & \multicolumn{5}{c}{ Min $65 \%$} \\
\hline
\end{tabular}

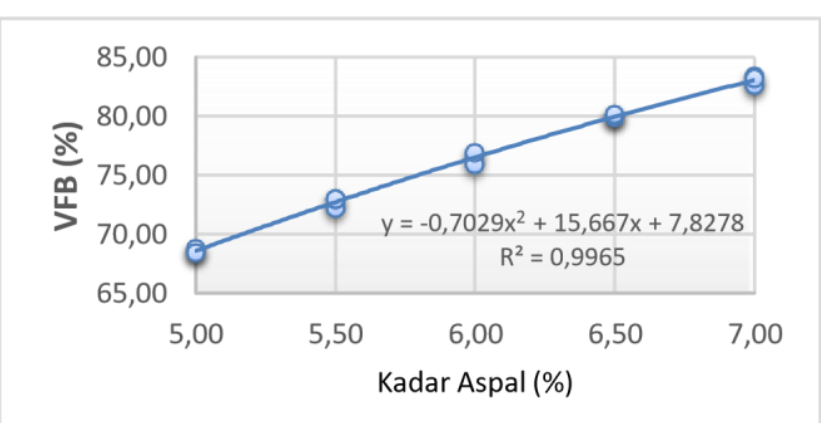

Gambar 6. Hubungan kadar aspal terhadap VFB

\section{Pembahasan}

Berdasarkan hasil pengujian karakteristik campuran beraspal AC-WC pengujian Marshall Konvensional diperoleh karakteristik campuran beraspal yang memenuhi semua spesifikasi yaitu stabilitas adalah kemampuan lapisan perkerasan menerima beban lalu lintas tanpa terjadi perubahan bentuk alur ataupun bleeding, flow adalah perbandingan lurus, semakin besar pula flow nya, dan begitu juga sebaliknya. VIM adalah rongga dalam campuran merupakan rongga yang tercipta akibat terjadinya pencampuran antara bahan bahan agregat kasar, agregat halus, filler,dan aspal yang telah di campur dan dilakukan proses pemadatan, VMA adalah rongga antara mineral agregat yang tercipta akibat adanya proses pencampuran antara agregat halus, agregat kasar dan filler,atau biasa di sebut rongga yang tercipta karna adanya pertemuan antar agregat, dan VFB adalah rongga yang tersisi aspal merupakan rongga rongga VMA yang terisi oleh aspal, yang dikeluarkan oleh Ditjen Bina Marga dalam Spesifikasi Umum Bina Marga Tahun 2018 Revisi 3.

\section{KESIMPULAN}

Karakteristik agregat atau batu dengan pasir yang berasal dari Sungai Mawa Kecamatan Cendana serta aspal penetrasi $60 / 70$ untuk campuran AC-WC memenuhi standar Bina Marga.

Komposisi campuran AC-WC yaitu agregat kasar $36,90 \%$, agregat halus (Pasir) 50,30\%, Filler 5,80\% dengan kadar aspal optimum $7 \%$. 
Berdasarkan hasil pengujian karakteristik campuran beraspal AC-WC melalui pengujian Marshall Konvensional diperoleh karakteristik campuran beraspal yang memenuhi semua spesifikasi yaitu stabilitas, flow, VIM, VMA, dan VFB yang dikeluarkan oleh Ditjen Bina Marga dalam Spesifikasi Umum 2018. Hasil uji Marshall Immersion (Indeks Kekuatan Sisa) pada campuran Laston ACWC menggunakan agregat Sungai Mawa Kecamatan Cendana memenuhi standar/spesifikasi Bina Marga yaitu minimal $90 \%$.

\section{DAFTAR PUSTAKA}

[1] Alpius and A. Kusuma, "Performance of Laston AC-WC Mixture Using Asbuton LGA and Fakfak Materials," Jour Adv Res. Dyn. Control Syst., vol. 11, no. 7, Art. no. 7, 2019.

[2] Direkorat Jenderal Bina Marga, Spesifikasi Umum Bina Marga 2018 untuk Pekerjaan Konstruksi Jalan dan Jembatan. Jakarta Indonesia: Kementerian Pekerjaan Umum dan Perumahan Rakyat, 2018.

[3] C. Kamba, "Pengaruh Penentuan Kadar Aspal Optimum Terhadap Kualitas Desain Campuran
Beraspal," in Seminar Nasional Teknik Sipil UKIPaulus, Makassar, 2013, vol. 1, pp. 58 - 69.

[4] Sumardi, R. Rachman, and J. Tanijaya, "Study of the Use Bagasse Ash as a Filler Replacement to Characteristics Asphalt Concrete," Int. J. Sci. Eng. Sci., vol. 3, no. 8, Art. no. 8, 2019, doi: 10.5281/zenodo.3408011.

[5] R. Krebs D. and R. Walker D., Highway Materials,. Michigan: McGraw-Hill, Universitas Michigan, 1971.

[6] R. Rachman, "Pemanfaatan Batu Gunung Bottomale Toraja Utara sebagai Campuran Laston," J. Tek. Sipil Dan Teknol., vol. 6, no. 1, Art. no. 1, 2020.

[7] Fani. L. A, Irianto, Elizabeth, and Alpius, "Pemanfaatan Agregat Sungai Wanggar Kabupaten Nabire Sebagai Bahan Campuran ACWC dan AC-BC," Paulus Civ. Eng. J. Ojsukipaulusacid, vol. 1, no. 2, Art. no. 2, 2019.

[8] Alpius, "Campuran HRS-WC Menggunakan Agregat Batu Gunung Desa Palipu Kecamatan Mengkendek Tana Toraja," in Konferensi Nasional Teknik Sipil (KoNTekS) - 13, Banda Aceh, 2019, vol. 1, pp. 431-441. 